\title{
Characterisation of the humification degree of peat soil under sago cultivation by using FTIR and $\mathrm{C} / \mathrm{N}$ ratio
}

\author{
Isaac John Umaru ${ }^{1,2 *}$, Benedict Samling 1 \\ 1 Faculty of Resource Science and Technology, Universiti Malaysia, 94300 Kota Samarahan, Sarawak, Malaysia 2 Department of \\ Biochemistry Federal University Wukari, Taraba State, Nigeria
}

\begin{abstract}
Sago palm are among the intensively cultivated crops on peatlands in Sarawak. However, a number of problems in large scale sago cultivation have been highlighted. One of the problems is the trunking ability of sago palm. The study attempted to examine the correlation between peat soil characteristics in term of molecular structure and the growth performance of sago palm. For this purpose, peat soil samples from Sg Talau plantation in Mukah Sarawak were studied. Functional group of the peat samples and their relations with the sago growth were studied. FTIR was used to identify the four main molecular structures that involve in humification of peat soil which are alcohols, aliphatic hydrocarbons, carboxylic acid and polysaccharides. Elemental analysis was determine by calculate $\mathrm{C} / \mathrm{N}$ ratio and found correlated with the peat maturity. Humification index was calculated by using the ratio of main functional group to polysaccharide.
\end{abstract}

Citation: Umaru IJ, Samling B (2018) Characterisation of the humification degree of peat soil under sago cultivation by using FTIR and C/N ratio, GJBAHS 7: 6.

Received: November 09, 2018; Accepted: December 27, 2018; Published: December 31, 2018

Copyright: (C2018 Umaru IJ, et al. This is an open-access article distributed under the terms of the Creative Commons Attribution License, which permits unrestricted use, distribution, and reproduction in any medium, provided the original author and source are credited.

Competing interests: The authors have declared that no competing interests exist.

Sources of funding: No funding.

*Email: umaruisaac@gmail.com

\section{Keywords:}

Peat soil, FTIR, Humification index, C/N ratio

\section{Introduction}

Malaysia is one of the largest producers of sago contributing to a total export of 47,000 metric ton valued at RM 81 million. Sago palm industry has been recognized for its contribution towards economic growth in Malaysia after oil palm, rubber and coconut.

Starches are normally derived from cereals such as corn, wheat and sorghum. Cassava root (tapioca) is also a source of starch. However, these types of crops normally grow on selective soil properties and climate. High maintenance is needed to make sure the crops grow well and produce starch. The growth of the crops is also affected by plant diseases which can only be controlled or prevented by advanced expensive treatment [1].
Sago starch is another source of starch that is harvested from the trunk of sago palms (Metroxylon sagu). Every trunk can produce up to $200 \mathrm{~kg}$ of dry starch. It is one of the tropical crops that can tolerate swampy and peaty condition with low pH. Sago is a crop with low maintenance; it does not require special treatment for the soil condition [2].

Peat soil is defined as soil that contains at least 30 percent of organic compounds resulting from decomposition of plant and animal residues including trees, fungi, animals and insects via biological process. It is formed when the accumulation of organic matter exceeds the rate of decomposition [3].

During the degradation process, physical, chemical as well as weathering processes also take place before the soil is ready for agriculture activities. The ability of peat in trapping water is described by Krumins, et al. [4]; this characteristic renders peat 
more acidic than other soil types with the ability to hold large amount of nutrients which is suitable for crop growth.

These properties have opened up opportunities for large scale cultivation on peat. Sago is one of the very few crops that can tolerate the low $\mathrm{pH}$ condition. In Sarawak, about 54,905 hectares of peatland has been exploited for sago cultivation; in Mukah alone, a total of 30,000 hectares was allocated for this purpose by the Land Custody Development Authority (LCDA). Sago plantation is identified as Mukah's niche agricultural-based product; the Crop Research and Application Unit (CRAUN) of LCDA has invested tremendously to carry out research relating to sago to identify its potential for pharmaceutical, food and cosmetics applications.

The quality of peat is determined by the content of organic compound, often referred to as humic substances (HS). Humic substances (HS) are defined as amorphous, polymeric and brown colored substances [5]. HS are essential and major components in peat. It is also the most abundant organic components present in the environment. HS can affect the physical and chemical properties of soil. HS is primarily characterized by the presence of oxygen-containing functional groups such as $\mathrm{COOH}$ and

-OH [6]. Humic substances can be classified into three categories, namely humic acid, fulvic acid and humin. According to Raposo, et al. humin is the major components in HS.

Although sago has been known to tolerate well on peat, the growth of sago is found to suffer on some peatland. Some sago trees are unable to produce trunk after 5 to 7 years. It is suspected that the degree of humification of peat may have contributed to this problem. According to Klavins \& Purmalis [7], humification is the transformation of macro- morphologically identifiable matter into amorphous compounds. The degree of humification determines the fertility of peat soil; typically, peat soil with a low $\mathrm{C} / \mathrm{N}$ ratio suggests higher degree of humification which implies greater fertility. Carbon to nitrogen ratio is a proxy to understand the sedimentary organic matter which will lead to information about the decomposition of organic material. If the organic material contain more nitrogen compared to carbon, the $\mathrm{C} / \mathrm{N}$ ratio will low. Hence, nitrogen is released to the soil.

\section{Problem statement}

Two main large scale sago plantations are found in Dalat and Mukah, Sarawak. With the low maintenance and well tolerating nature of sago, the crop is anticipated to be a viable commodity on peat soil nonetheless; the cultivation of sago has suffered issues on its growth performance and harvesting yields. Many palms struggle to form trunks after 17 years of plantation, especially on deep peat; they are often called the non-trunking palms. Sim, et al. [8] compared the peat soil of the trunking and non-trunking blocks concluding that the latter, planted at the deep peat area, suffered nutrient deficiency. Besides, Flach, [8] reported that the immature sago palms are mainly found in area subjected to flood which have affected the starch storage capacity. Other studies in molecular aspect were also conducted to identify the cause of underperforming growth of sago palm [9]. Unfortunately, the results were inconclusive due to insignificant differences in the tested parameters. Veloo, et al. [10] concluded that the growth of oil palm is related to the characteristic of the peat soil. To date, the failures in formation of trunk in some sago palms planted on peatland remain unknown. On deep peat in particular, some palms were found to produce decent trunk whilst some struggle the formation of trunk. It is believed that the growth is closely associated with the degree of humification of peat. Unfortunately, there is limited study on the profile of humification degree on peat soil under sago cultivation.

\section{Sample collection}

Peat soil samples were collected from Sg. Talau Plantation in Mukah, Sarawak (Figure 1). The soil samples were collected from the trunking and nontrunking sago (Figure 2) palms at a plot characterized with peat depth of $5 \mathrm{~m}$. A total of 7 samples were collected from trunking and nontrunking plots, respectively. Peat soil samples without plantation activity were also collected and are referred to as the control. The soil samples were augured to 5 depths $(0-20 \mathrm{~cm}, 20-40 \mathrm{~cm}, 40-60 \mathrm{~cm}$, $60-80 \mathrm{~cm}$ and $80-100 \mathrm{~cm})$. The diameter of trunking sago palms at breast height was also measured and the measurement recorded was between 45 and $57 \mathrm{~cm}$. 


\section{Sample preparation}

The soil samples were oven-dried at a temperature of $30^{\circ} \mathrm{C}$ for 24 hours. The oven-dried samples were then ground into fine particles by using mortar and pestle then sieved by using 1-mm sieve.

\section{FTIR analysis}

ATR-FTIR of Thermo Scientific (Thermo Nicolet Analytical Instruments, Madison, WI) was used to analyze all the samples. Before and after used the FTIR, the surface of the ATR was cleaned by using $95 \%$ ethanol to remove any residual. The background of each spectrum was recorded as bare ATR crystal. Each sample was scanned in triplicates.

The spectra profile in csv format were analysed with the peak detection and matching algorithm reported by Sim and Ting [11]. All data in csv format were converted into mat files and analysed using Matlab. With this algorithm, the peaks were detected, assigned and matched across samples to obtain a peak table with rows corresponding to sample and columns to variables. The algorithm was applied on a dataset of 186 spectra of peat soil.

\section{Total carbon and nitrogen analysis}

Total carbon and nitrogen in the samples was analyzed by using LECO Total Carbon Nitrogen Analyzer controlled by TruMac software. All the samples were heated at $60^{\circ} \mathrm{C}$ for 24 hours to eliminate moisture in the samples. The $\mathrm{C} / \mathrm{N}$ ratios were calculated by determining the ratio between $\mathrm{C}$ and $\mathrm{N}$ contents respectively.

\section{Statistical analysis}

Principal Component Analysis (PCA) was used to evaluate the clustering pattern for different groups of samples. Analysis of Variance (ANOVA) was used to evaluate the difference in mean for different group of samples at $95 \%$ significance level. t-test was used to compare the means of the two different sample groups. All analysis was performed using Matlab 2013a (The Math Works Inc., Natick, MA, USA).

\section{Result and Discussion}

\section{Result}

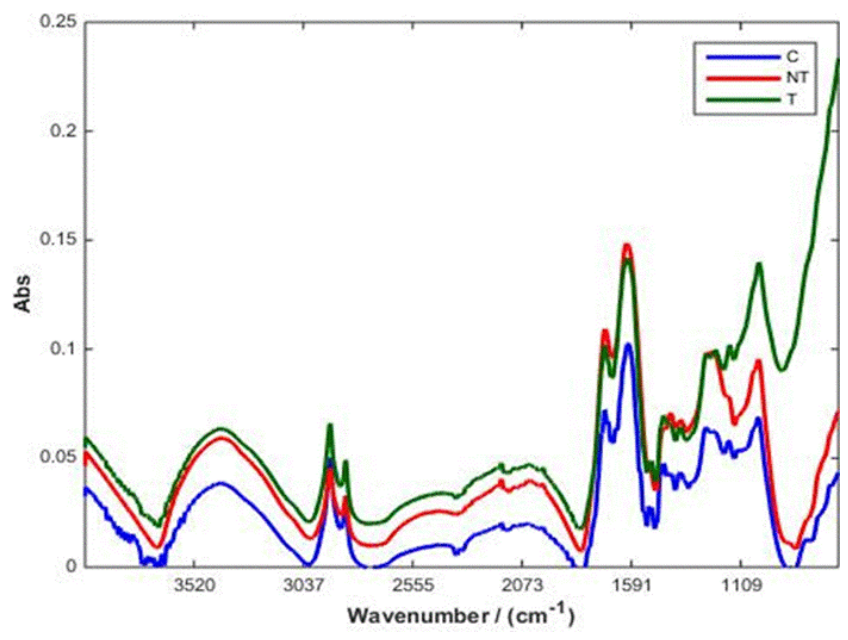

Figure 1: Peat soil profile for uncultivated, non-trunking and trunking plot.

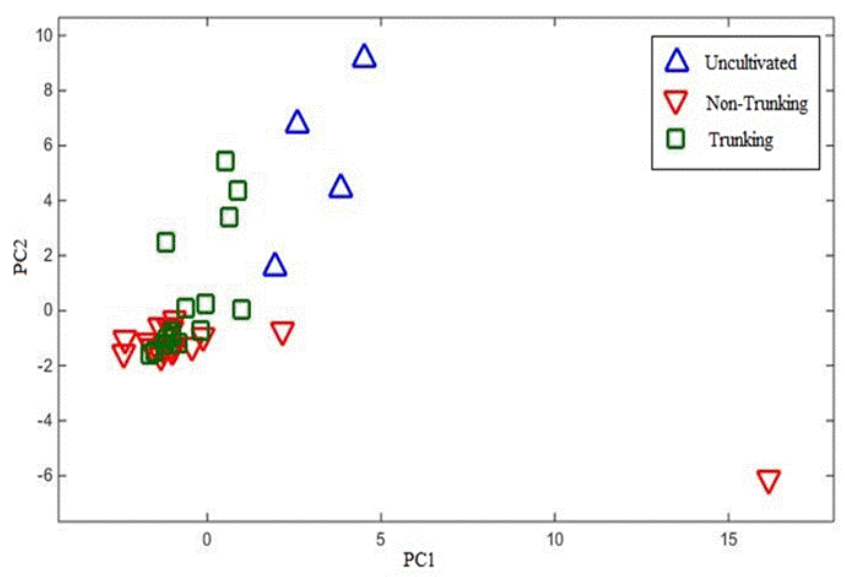

Figure 2: The scores plot of $\mathrm{PC} 2$ versus $\mathrm{PC} 1$ for the peak table of FTIR spectra obtained from cultivated and uncultivated peat at $0-20 \mathrm{~cm}$ depth.

\section{Discussion}

The FTIR profile of peat soil obtained from the uncultivated (Control) and Cultivated (Nontrunking and Trunking) plots are illustrated in Figure 1. The spectra illustrate similar profile with major absorption bands identified at $1450 \mathrm{~cm}^{-1}$, $1505 \mathrm{~cm}^{-1}, 2849 \mathrm{~cm}^{-1}$ and $2920 \mathrm{~cm}^{-1}$, similar to the findings reported by Biester et al. Other bands at $1070-1030 \mathrm{~cm}^{-1}$ are attributed to $\mathrm{C}-\mathrm{O}$ stretching of polysaccharide; $1450 \mathrm{~cm}^{-1}$ belongs to $\mathrm{O}-\mathrm{H}$ deformation and C-O stretching of phenols [12]. At $1505 \mathrm{~cm}^{-1}$, the weak absorption band indicates the presence of $\mathrm{C}=\mathrm{C}$ aromatic or $\mathrm{CO}$ amide group. The 
functional groups of the common bands are summarized in Table 1.

Table 1: Common functional groups detected in all samples.

\begin{tabular}{ll}
\hline Wavenumber $\mathbf{c m}^{-1}$ & Functional Groups \\
\hline 1070 & C-O stretching of polysaccharide \\
\hline 1159 & C-O stretching of alcoholic \\
\hline 1450 & Aliphatic C-H deformation \\
\hline 1605 & C=C stretching in benzene \\
\hline 2918 & C=C aromatics \\
\hline 3404 & C=O stretching of carboxylic acid \\
\hline
\end{tabular}

The spectra were analyzed with the automated peak detection and matching algorithms as reported by Sim and Ting producing a peak table with rows corresponding to samples and columns to wave numbers. The peak table was subjected PCA to reveal the underlying pattern of the data. Figure 3 shows the scores plot of PC 2 against PC1 according to cultivated (trunking and non-trunking) and uncultivated (control) plot at $0-20 \mathrm{~cm}$ depth. Observably, the control peat is distinguishable from the cultivated samples. The blue, red and green markers indicate control, non-trunking and trunking samples, respectively. It suggests that the control samples have different characteristics in term of chemical compositions compared to those from the cultivated plot.

The decomposition process at $20 \mathrm{~cm}$ depth give changes to the structure of organic matter [12]. During decomposition process, the complex compound from the fresh plants litter was degraded. The changes in the compounds in peat soil were used as the humification proxies [13].

Overall, the $\mathrm{C} / \mathrm{N}$ ratio is relatively lower at $0-20 \mathrm{~cm}$ for uncultivated and cultivated plots with trunking samples demonstrating the lowest value. A low $\mathrm{C} / \mathrm{N}$ ratio suggests richer nitrogen reserve which is an evidence of greater fertility and an indication of higher humification degree Raghunadan and Sriraam [5] have likewise reported more decomposed peat at the surface soil. Statistically, there is a significant different between uncultivated and trunking samples $(\mathrm{p}<0.05)$. However, no significant different is deduced between uncultivated and non-trunking plot $(\mathrm{p}>0.05)$. Decomposition of tropical peatlands is primarily related to geographical and agricultural activities. As the depth increases, the $\mathrm{C} / \mathrm{N}$ ratios are found to increase for the three samples [14].

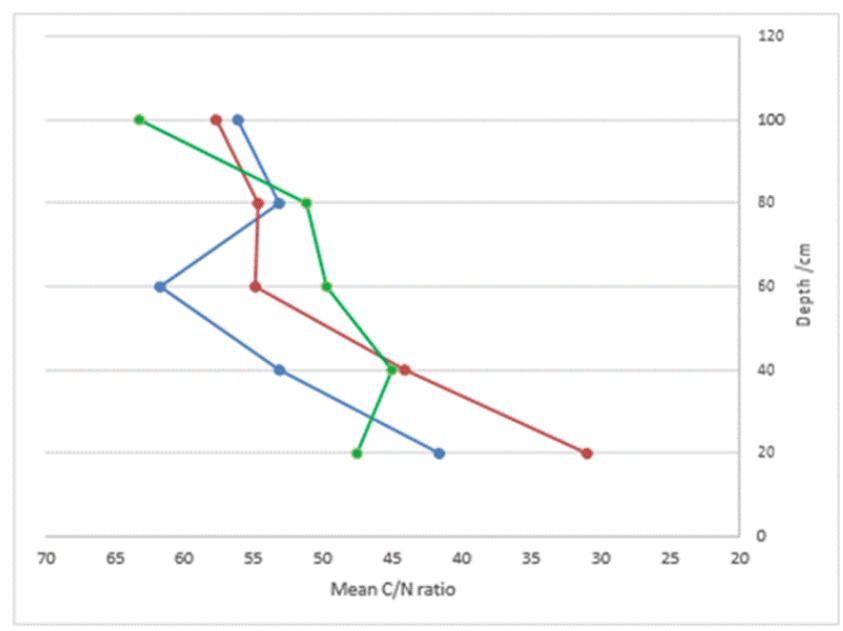

Figure 3: Mean of $\mathrm{C} / \mathrm{N}$ ratio for uncultivated and cultivated plot. Uncultivated (blue), cultivated trunking (red) and cultivated non-trunking (green).

This indicates that the peat at lower horizons is relatively less humified. This observation contradicts the findings of Rezanezhad, et al. [15] who reported that the humification degree of peat increased with depth. The upper parts of the peat are more exposed to continuous oxidation process hence is likely more decomposed [14]. At the bottom layer, the peat is characterized with undecomposed logs and tree branches hence are not suitable for agriculture activities. High carbon content in the bottom layer of the non-trunking plot is an indicator of immaturity of the peat which in turn implying lowers humification degree [16].

\section{Conclusion}

From the structural information of FTIR, it is found that the surface peat is more humified than that at the deeper horizon. The elemental analysis shows the $\mathrm{C} / \mathrm{N}$ ratio was low at the surface of the peat indicates the surface soil is humified. According to Wüst, et al. [17], tropical peat primarily from the woody trees with the roots penetrates until rooting zone. This finding was confirmed by Könönen, et al. [18] who describes that the tropical peat in Indonesia was mostly consist of undecomposed 
woody material. Veloo, et al. [19] found tropical peat in Sarawak contain woody material at deeper depth. According to the data, the molecular structure, carbon content and nitrogen content as well as humic acid ratio are sensitive proxies to determine the degree of humification of peat soil. Thus, the sago palm must not cultivate in deep peat [20-25].

\section{Recommendation}

In this research, it was observed that soil management is needed to make sure the surface of the peat soil being clear up periodically to minimize the accumulation of plant litter input which will slow down the humification process. Climate change is known to be another parameter that can affected the process of humification. Therefore, further study regarding the effect of climate changes to humification process is highly needed.

\section{References}

1. Heller C, Ellerbrock RH, Roßkopf N, Klingenfuß C, Zeitz J. Soil organic matter characterization of temperate peatland soil with FTIR-spectroscopy: effects of mire type and drainage intensity. Eur J Soil Sci 2015;66:847-858.

2. Hiroshi E, Slamet S, Chitoshi M, Shohei H, Tadashi M Sago palm (metroxylon sagu, arecaceae) production in the eastern archipelago of Indonesia: Variation in morphological characteristics and pith dry-matter yield. J Economic Botany 2016;54:197-206.

3. Dommain R, Cobb AR, Joosten H, Glaser PH, Chua AFL, et al. Forest dynamics and tip-up pools drive pulses of high carbon accumulation rates in a tropical peat dome in Borneo (Southeast Asia). J Geophys Res Biogeosci 2015;120:617-640.

4. Krumins J, Klavins M, Seglins V. Comparative study of peat composition by using FT-IR spectroscopy. Material Science and Applied Chemistry 2012;106-114.

5. Raghunandan, Sriraam AS. An overview of the basic engineering properties of Malaysian peats. Geoderma Regional 2017;11:1-7.

6. Martins Gomes ET, Berbara RLL, Pereira MG, Urquiaga SS, Tavares $\mathrm{OCH}$, et al. Effects of farmed managements in sandy soils on composition and stabilization of soil humic substances. Land Degradation \& Development 2017.

7. Klavins M, Purmalis O. Properties and structure of raised bog peat humic acids. Journal of Molecular Structure 2013;1050:103-113.

8. Sim S, Khan AJ, Mohamed M, Mohamed AM. The relationship between peat soil characteristics and the growth of sago palm (Metroxylon sagu). Sago Palm 2005;9-16.

9. Raposo JC, Villanueva U, Olivares M, Madariaga JM. Determination of humic substances in sediments by focused ultrasound extraction and ultraviolet visible spectroscopy. Microchemical Journal 2016;128:26-33.

10. Veloo R, Ranst EV, Selliah P. Peat Characteristics and its Impact on Oil Palm. J Life Sci 2014;33-40.

11. Sim SF, Ting W. An automated approach for analysis of fourier transform infrared (FTIR) spectra of edible oils. Talanta 2012;537-543.

12. Zaccone C, Sanei H, Outridge PM, Miano TM. Studying the humification degree and evolution of peat down a Holocene bog profile (Inuvik, NW Canada): A petrological and chemical perspective. Organic Geochemistry 2011;42(4):399-408.

13. Flach M. Sago Palm Metroxylon Sagu Rottb. Rome, Italy: Institut of Plant Genetics and Crop Plant research 1997.

14. Nabeya K, Nakamura S, Nakamura T, Fujii A, Watanabe $\mathrm{M}$, et al. Growth behavior of sago palm (Metroxylon sagu Rottb.) from transplantation to trunk formation. Agronomy and Crop Ecology 2015;209-217.

15. Rezanezhad F, Price JS, Quinton WL, Lennartz B, Milojevic T, et al. Structure of peat soils and implications for water storage, flow and solute transport: A review update for geochemists. Chemical Geology 2016;429:75-84

16. Uyguner CS, Bekbolet $M$. Implementation of spectroscopic parameters for practical monitoring of natural organic matter. Desalination 2005;176:47-55.

17. Wüst RAJ, Bustin RM, Lavkulich LM. New classification systems for tropical organic-rich deposits based on studies of the Tasek Bera Basin, Malaysia. Catena 2013;53(2): 133-163.

18. Könönen M, Jauhiainen J, Laiho R, Kusin K, Vasander H. Physical and chemical properties of tropical peat under stabilised land uses. J Mires \& Peat 2015;16:1-13.

19. Veloo R, Van Ranst E, Selliah P. Peat Characteristics and its Impact on Oil Palm Yield. NJAS - Wageningen J Life Sci 2015;72:33-40.

20. Higashikawa FS, Silva CA, Nunes CA, Sanchez-Mondero MA. Fourier transfrom infrared spectroscopy and partial least square regression for the prediction of substrate maturity indexes. Sci of Env 2014;470-471.

21. Biester H, Knorr KH, Schellekens J, Basler A, Hermanns YM. Comparison of different methods to determine the degree of peat decomposition in peat bogs. Biogeosciences 2014;11(10):2691-2707.

22. Ellen RF. Local knowledge and management of sago palm (Metroxylon sagu Rottboell) diversity in South Central Seram, Maluku, eastern Indonesia. J Ethnobiology 2006;26(2):258-298.

23. Kumar A, Srivastava AK, Gangwar S, Misra N, Mondal A. Combined experimental (FT-IR, UV-visible spectra, NMR) and theoretical studies on the molecular structure, vibrational spectra, HOMO, LUMO, MESP surfaces, reactivity descriptor and molecular docking of Phomarin. J Mol Struct 2015;94-101.

24. MOA. (2018, October). Retrieved from Department of Agriculture: http://www.doa.gov.my/

25. PELITA. (2018, October). Retrieved from Official Website of Land Custody and Development Authority: http://www.pelita.gov.my/ 